\title{
The Impact of Four Different Diets on Metabolic Syndrome
}

\author{
Yu Chao Zhang ${ }^{1,2}$, Wei Na Gao ${ }^{2,3},{\mathrm{Xia} \mathrm{Li}^{2} \text {, Yuan Tao Liu', Xiang Dong Wang }}^{2,4}$ \\ ${ }^{1}$ Department of Endocrinology, Qingdao Municipal Hospital, Qingdao, China, 266011; ${ }^{2}$ The Department of Cell Biology and \\ Neurosciences, Shandong University School of Basic Medical Sciences, Jinan, China, 250012; ${ }^{3}$ School of Medical Technology and \\ Engineering, Henan University of Science and Technology, Luoyang, China 471003; ${ }^{4}$ Key Laboratory of Protein Sciences for Chronic \\ Degenerative Diseases, China 250012
}

\begin{abstract}
Objectives To evaluate the effects of different diets on the risk of metabolic syndrome. Methods Five groups of female SD rats were fed a normal control (NC) diet, a high-protein (HP) diet, a high-fat diet (HF), a combination high-fat and high-protein diet $(\mathrm{HF}+\mathrm{HP})$ or a high-fat with cholesterol diet $(\mathrm{HF}+\mathrm{CHO})$, and the changes in body weight, insulin sensitivity and blood biochemical parameters were examined. Results The HF and $\mathrm{HF}+\mathrm{CHO}$ diets resulted in an increase in body insulin resistance, high blood TG, high blood cholesterol and high blood LDL, with the $\mathrm{HF}+\mathrm{CHO}$ resulting in larger changes than the $\mathrm{HF}$ diet. Furthermore, the $\mathrm{HF}+\mathrm{CHO}$ diet led to a decrease in $\mathrm{HDL}$, making it the most dangerous diet. However, the HF+HP diet also led to increased blood sugar and some insulin resistance. Conclusions Our findings indicate that the levels of fat and cholesterol should be carefully considered in future diet formulations for patients with or at risk of metabolic syndrome. A high protein diet may reduce the risk of insulin resistance and serum lipid level elevation, but its effects on kidney function remain unknown.
\end{abstract}

Key words: High-fat diet; High protein diet; Cholesterol; Insulin resistance; Metabolic syndrome

\section{Introduction}

Metabolic syndrome includes disturbances in glucose and insulin metabolism, abdominal obesity, distributed weight, mild dyslipidemia, a pro-inflammatory state, and hypertension, with the subsequent development of obesity, type II diabetes (TIID), and cardiovascular disease [1]. The pathological effects of this syndrome are attributable to insulin resistance, with an excessive flux of fatty acids also having been implicated in the pathogenesis [2]. Both genetic and environmental factors contribute to the development of metabolic syndrome [3,4]. Diet is one of the most important factors that have effects on the development and progression of metabolic syndrome.

A number of studies have found that a diet with high saturated fat or sucrose significantly increases weight gain and obesity, as well as impairing glucose tolerance and cognitive functions and leading to insulin resistance [5-7]. A high-fat or high-sucrose diet could make normal rats obese, which was also associated with hyperlipidemia, hyperinsulinemia and glucose intolerance [8-10]. On the other hand, moderate weight loss, particularly a reduction in adipose tissue, has been shown to improve insulin sensitivity, glycemic control, and dyslipidemia in overweight subjects with insulin resistance [11-13]. With regard to energy expenditure, protein is known to have the highest and most prolonged thermic effect of the separate macronutrients $(20 \% \sim 30 \%)$, followed by carbohydrates $(5 \% \sim 15 \%)$ and fat $(0 \% \sim 3 \%)$ [14]. Previous

Correspondence author : Xiang Dong Wang, $\mathrm{PhD}$, The Department of Cell Biology, Shandong University School of Medicine 44 Wenhua Road West, Jinan, China 250012; Tel +86 5318838 2046; Fax +86 531 8838 2502; Email: xdongw@sdu.edu.cn studies have indicated that a replacement of some dietary carbohydrate with protein promoted a reduction in food intake and body weight loss [15-19]. However, the effects of a high protein diet on overall health and metabolic syndrome remain unknown.

A high-fat diet has been shown to impair insulin regulation [7], but the effects of long-term exposure to a high-protein diet, and of a diet combining high-fat and high-protein, on glucose or insulin regulation and metabolism have not been tested. Low-density lipoprotein cholesterol is one of the markers used for determining the risk of cardiovascular disease [20], so the effects of a high-fat diet with high cholesterol on metabolic syndrome also need to be clarified. The objective of the present study was to compare the effects of four different diets on metabolic syndrome. The results of this study will provide useful information for clinicians, researchers, and the general public with regard to dietary recommendations to reduce the risk of metabolic syndrome.

\section{Methods and Materials Experimental animals}

Female Sprague-Dawley (SD) rats, aged 7 weeks and weighing $180 \pm 20 \mathrm{~g}$, were purchased from the Experimental Animal Center of Shandong University. The rats were maintained under controlled light $(12: 12 \mathrm{~h}$ lightdark cycle with lights on at 7 a.m.), temperature $\left(23 \pm 1^{\circ} \mathrm{C}\right)$ and humidity (55\%). The animals were given food and distilled water ad libitum during the experimental period. The rats were fed a standard basal diet for 1 week to adapt to the experiment conditions. After the adaptation period, the rats were randomly divided into five groups and fed one of the following diets for 8 weeks: NC group: normal 
diet, $\mathrm{n}=12$; (2) HP group: high-protein diet, $\mathrm{n}=12$; (3) HF group: high-fat diet, $\mathrm{n}=12$; (4) $\mathrm{HF}+\mathrm{HP}$ group: high-fat + high-protein diet, $\mathrm{n}=12$; (5) $\mathrm{HF}+\mathrm{CHO}$ group: high-fat + cholesterol diet, $\mathrm{n}=12$.

The food consumption was measured at 9 a.m. daily, and the body weight was recorded weekly at the same time of day. Animal experiments were carried out according to the 'Principles of Laboratory Animal Care' established by the National Institutes of Health, and approved by the 'Animal Care and Use Committee' of Shandong University (NO. MECSDUMS 2011055).

\section{Diets}

The detailed composition of the experimental diets is provided in Table 1. The basal diet was purchased from the Experimental Animal Center of Shandong University. Casein, sucrose, lard, cholesterol, and sodium cholate were purchased from Anhui TianQi chemical Technology CO., Ltd (China).

Table 1 Compositions of the five diets $(\mathrm{g} / 100 \mathrm{~g})$ used in the present study.

\begin{tabular}{lccccc}
\hline Component & NC & HP & HF & HF+HP & HF+CHO \\
\hline Casein & 20 & 36 & 20 & 30 & 20 \\
D,L-methionine & 0.3 & 0.3 & 0.3 & 0.3 & 0.3 \\
Mineral mix & 3.5 & 3.5 & 3.5 & 3.5 & 3.5 \\
Vitamin mix & 1 & 1 & 1 & 1 & 1 \\
Cellulose powder & 5 & 5 & 5 & 5 & 5 \\
Choline bitartrate & 0.2 & 0.2 & 0.2 & 0.2 & 0.2 \\
Corn oil & 4 & 4 & 4 & 4 & 4 \\
Sucrose & 20 & 20 & 20 & 20 & 20 \\
Corn starch & 46 & 30 & 26 & 26 & 33.5 \\
Lard & - & - & 20 & 10 & 10 \\
Cholesterol & - & - & - & - & 2.5 \\
Total (\%) & 100 & 100 & 100 & 100 & 100 \\
kcal/100 g diet & 385.9 & 385 & 485.9 & 435.9 & 425.9 \\
Calories from fat (\%) & 9.3 & 9.3 & 44.5 & 28.9 & 29.6 \\
Calories from & 68.6 & 52 & 38 & 42.3 & 50.4 \\
carbohydrates (\%) & & & & & \\
Calories from protein & 21 & 37.6 & 16.7 & 27.8 & 19.1 \\
(\%) & & & & & \\
\hline
\end{tabular}

\section{Blood sample preparation and biochemical analysis}

After they were fed different diets for 8 weeks, all rats underwent a $12 \mathrm{~h}$ fast. All of the rats were then sacrificed after being anesthetized with $10 \%$ chloral hydrate, and blood samples were obtained by venous puncture. The blood was allowed to coagulate and centrifuged at 3000 rpm for $10 \mathrm{~min}$ at $4^{\circ} \mathrm{C}$ and serum was stored at $-80^{\circ} \mathrm{C}$ until analysis. The serum concentrations of glucose (GLU), cholesterol (CHO), triglycerides (TG), high-density lipoprotein (HDL) and low-density lipoprotein (LDL) were analyzed using an auto-analyzer (Hitachi 7100, Japan) by routine procedures. Serum insulin (INS) was assayed by radioimmunoassay using ${ }^{125}$ I-labeled insulin (Beijing North Institute of Biological Technology, China). The insulin resistance index from serum insulin and glucose was estimated by the HOMA (homeostasis model assessment) parameter: $\mathrm{HOMA}=$ insulin $(\mu \mathrm{IU} / \mathrm{ml}) \times$ glucose $(\mathrm{mM}) / 22.5$ [21-23].

\section{Statistical analysis}

All data are expressed as the means \pm SEM. Differences between groups were examined by Student's $t$-test or ANOVA using SPSS 17.0 software. A value of $P<0.05$ was considered statistically significant.

\section{Results}

Food intake, energy intake and body weight

As shown in Table 1, the energy content of the high-fat diet was significantly higher than that of the normal control diet (HF: $485.9 \mathrm{kcal} / 100 \mathrm{~g}$; HF+HP: $435.9 \mathrm{kcal} / 100 \mathrm{~g}$; HF+CHO: $425.9 \mathrm{kcal} / 100 \mathrm{~g}$ vs. NC: $385.9 \mathrm{kcal} / 100 \mathrm{~g}$ ). The food intake per day was similar among most of the groups, although the HF group exhibited significantly lower food intake than the other groups (Table 2). The energy intake of $\mathrm{HF}$ and $\mathrm{HF}+\mathrm{HP}$ groups was markedly higher than that of the $\mathrm{NC}$ and $\mathrm{HF}+\mathrm{CHO}$ groups. Body weights were measured weekly, and the weight changes of the various groups are presented in Table 2 and Figure 1. The weight gain in the rats fed the $\mathrm{HF}$ diet or $\mathrm{HF}+\mathrm{CHO}$ diet was significantly greater than that in the rats fed the basal (NC) diet after 8 weeks $(P<0.05)$. The body weights of rats fed the HP or combination $\mathrm{HF}+\mathrm{HP}$ diet were not significantly different from that of the control rats.

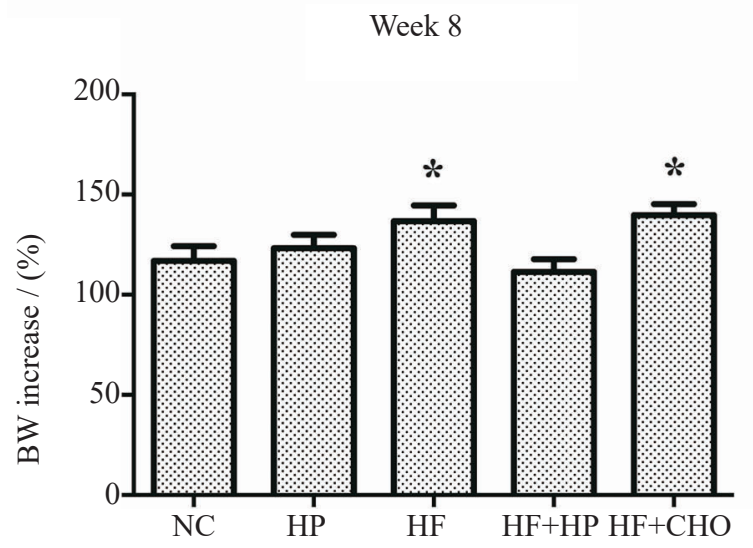

Figure 1 Weight changes of animals fed five different diets for 8 weeks. NC: basal normal control diet $(\mathrm{n}=12)$; HF: high-fat diet ( $\mathrm{n}$ = 12); HP: high-protein diet $(\mathrm{n}=12)$; HF+HP: high-fat and highprotein diet $(\mathrm{n}=12)$; $\mathrm{HF}+\mathrm{CHO}$ : cholesterol added to the highfat diet $(n=12)$. Values were expressed as the mean weight gain relative to the original body weight (\%) (mean \pm SEM). $* P<0.05$ versus the $\mathrm{NC}$ group. 


\section{Insulin resistance}

The fasting blood glucose and insulin levels were determined in the rats after 8 weeks of the different diets (Figure 2). The $\mathrm{HF}+\mathrm{CHO}, \mathrm{HF}$ and $\mathrm{HF}+\mathrm{HP}$ diets all resulted in increased blood insulin levels. The HOMA-IR results are shown in Figure 3. The trend in insulin resistance for the rats fed the different diets was $\mathrm{HF}+\mathrm{CHO}>\mathrm{HF}>\mathrm{HF}+\mathrm{HP}$.

A

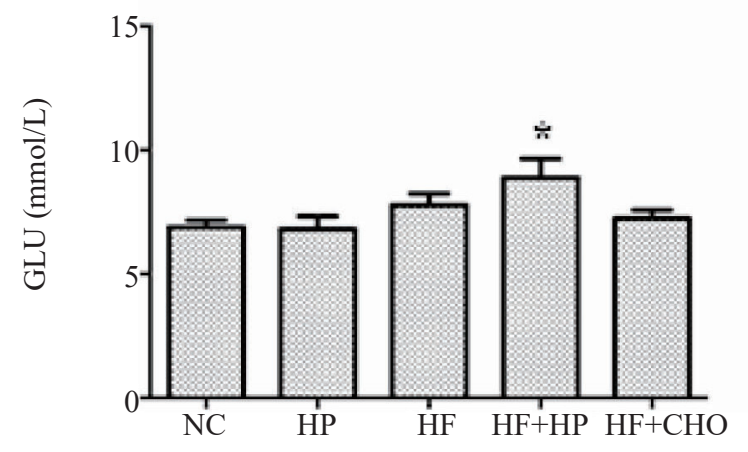

B

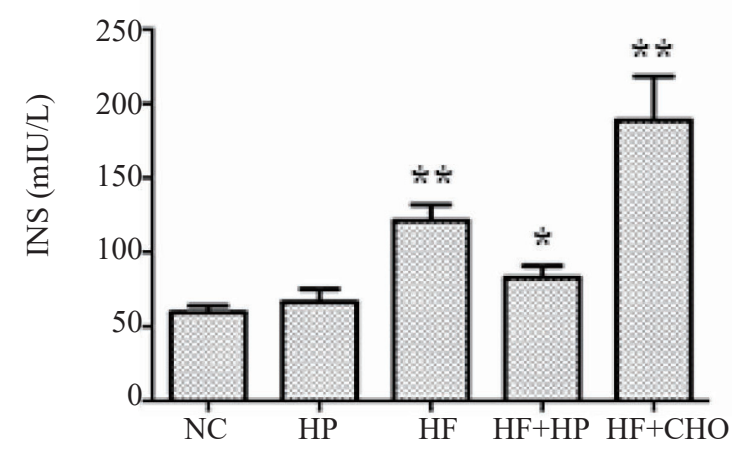

Figure 2 The serum glucose and insulin levels in rats fed five different diets for 8 weeks after a 12h fast. The values are expressed as the means \pm SEM. $* P<0.05$, $* * P<0.01$ versus the NC group. GLU: glucose; INS: insulin.

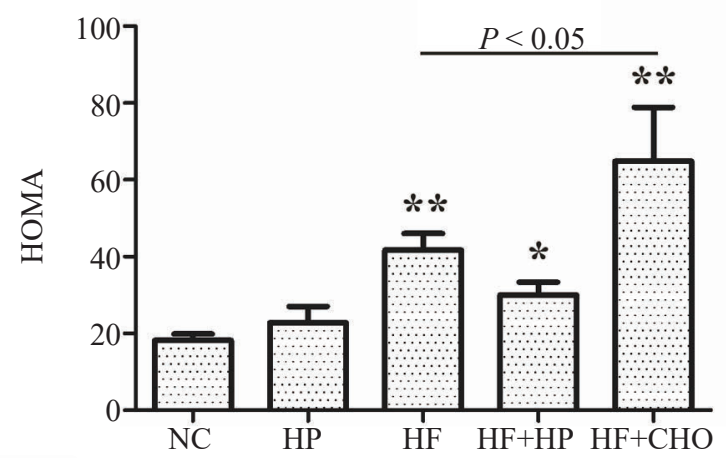

Figure 3 The results of a HOMA analysis of rats fed five different diets for $\mathbf{8}$ weeks. The HOMA levels were calculated using the Matthews formula (HOMA $=$ insulin $\times$ glucose $/ 22.5)$. Values are expressed as the means \pm SEM. $* P<0.05, * * P<0.01$ versus the NC group.

\section{Serum biochemical parameters}

The metabolic parameters (including $\mathrm{CHO}$, TG, HDL and LDL) at week 8 are summarized in Figure 4. Rats fed the $\mathrm{HF}$ or $\mathrm{HF}+\mathrm{CHO}$ diet had markedly elevated serum cholesterol and triglyceride concentrations in comparison with rats fed the basal $(\mathrm{NC}) \operatorname{diet}(P<0.01)$. Compared with the $\mathrm{HF}+\mathrm{CHO}$ group, the HF group showed significant increases in the CHO, TG and LDL blood concentrations. The HF group had a higher HDL concentration than the NC group $(P<0.05)$, while the $\mathrm{HF}+\mathrm{CHO}$ group had a markedly lower HDL concentration $(P<0.05)$. The concentrations of $\mathrm{CHO}, \mathrm{TG}, \mathrm{HDL}$ and LDL not significantly different in the groups fed the high-protein diet and the basal (NC) diet $(P>0.05)$. However, the rats in the HF+HP group showed markedly lower total cholesterol and LDL concentrations than the HF group $(P<0.05)$. This finding suggests that the high protein in the $\mathrm{HF}+\mathrm{HP}$ diet was able to reduce the effects of high fat on the serum lipid and LDL levels.

\section{Discussion}

In present study, we investigated the effects of different diets $(\mathrm{NC}, \mathrm{HP}, \mathrm{HF}, \mathrm{HF}+\mathrm{HP}, \mathrm{HF}+\mathrm{CHO})$ on the weight gain, blood glucose and metabolic parameters in female SD rats. The data demonstrated that rats fed a high-fat diet had increased body weights, impaired blood glucose regulation and metabolic disorders. We observed that the addition of cholesterol to a high-fat diet had additional deleterious effects on insulin resistance and metabolic syndrome. However, rats fed a high-protein diet did not show any significant change in body weight, and did not develop insulin resistance. In fact, the HP group showed a similar metabolic profile to the NC group. In addition, the inclusion of high protein in the HF+HP diet apparently helped to prevent the increases in serum lipid and LDL levels incurred by a high-fat diet.

Previous studies have also suggested that a HF diet leads to greater weight gain in rodents and accelerates the development of insulin resistance [24]. In our study, the high-fat diet, especially a $\mathrm{HF}+\mathrm{CHO}$ diet, led to significant weight gain in the rats at the end of the 8 weeks. The HOMA-IR values also indicated that rats exposed to a high-fat diet had impairments in blood glucose regulation and irregularly higher insulin secretion, while the addition of cholesterol to this diet resulted in more severe insulin dysregulation. These results suggest that rats fed a high-fat diet for a long period of time develop insulin resistance, and additional cholesterol in addition to high fat results in more severe insulin resistance.

Clinical, genetic, and experimental studies have shown that high serum levels of cholesterol or low-density lipoprotein cholesterol are associated with atherosclerosis and an increased risk of coronary heart disease [25,26]. In particular, hypercholesterolemia is a risk factor that contributes to the development and progression of atherosclerosis and subsequent cardiovascular disease 
[27]. The typical Western diet contains both high fat and high cholesterol, and a previous 12 -week feeding study showed that this diet resulted in accelerated atherosclerosis [28]. Emerging data suggest that hypercholesterolemia has stimulatory effects on adaptive immunity to further promote atherosclerosis and inflammatory diseases [29]. One research study showed that there was no association between egg consumption and cardiovascular disease in non-diabetic patients [30]. However, the data also showed that there was a $42 \%$ increase in the incidence of type II diabetes in the high-egg consumption group and a $69 \%$ increase in overall cardiovascular disease among the subgroup of existing diabetic patients in the high-egg consumption group. Thus, diabetic subjects who consumed more cholesterol had an increased relative risk of atherosclerosis and subsequent fatal coronary heart disease [31].

The HDL cholesterol plasma levels are inversely related to the risk of cardiovascular disease [32]. A study in subjects from North Karellan demonstrated that the dietary fat and cholesterol intake could modulate the apo-lipoprotein E isoforms of plasma cholesterol in blood samples [33]. In the present study, the serum levels of TG, CHO, LDL and HDL were significantly elevated in the HF group compared to the $\mathrm{NC}$ group. The presence of additional cholesterol in the $\mathrm{HF}$ diet further increased the levels of TG, $\mathrm{CHO}$ and LDL. These results suggest that while a high-fat diet plays a role in metabolic risk, additional cholesterol in a HF diet might worsen this risk. Interestingly, rats fed a HF diet showed not only a markedly higher serum LDL level, but also a small increase in the serum HDL level.

High-protein diets have been considered useful to increase energy expenditure. The relatively high-protein diets typically used for weight loss and weight maintenance derive at least $25 \% \sim 30 \%$ of their energy from protein [34]. By doubling the relative protein content of the general diet from $10 \% \sim 15 \%$ to $20 \% \sim 30 \%$, the calculated grams of protein ingested increased from $44 \sim 67 \mathrm{~g} / \mathrm{d}$ to $80 \sim 120 \mathrm{~g} /$ d when the diet was energy-balanced to $2000 \sim 2500 \mathrm{kcal} /$ $\mathrm{d}$ in humans [34]. Some research has shown that long-term consumption of a high-protein diet (50\% protein) in rats has no deleterious effects, and led to a sharp reduction in white adipose tissue [35].

Table 2 Effects of excess protein or fat on the food intake, energy intake and body weight gain.

\begin{tabular}{lccccc}
\hline & NC & HP & HF & HF+HP & HF+CHO \\
\hline Food intake (g/day) & $25.41 \pm 0.55$ & $24.67 \pm 0.62$ & $22.51 \pm 0.34^{*}$ & $24.25 \pm 0.50$ & $23.97 \pm 0.57$ \\
Energy intake (kcal/day) & $97.86 \pm 1.19$ & $95.18 \pm 1.51$ & $109.38 \pm 1.67^{*}$ & $105.74 \pm 1.20^{*}$ & $102.09 \pm 1.67$ \\
Body weight gain (g/day) & $0.61 \pm 0.03$ & $0.83 \pm 0.03$ & $1.31 \pm 0.03^{*}$ & $0.41 \pm 0.02$ & $1.42 \pm 0.03^{*}$ \\
\hline
\end{tabular}

* significantly different $(P<0.05)$ compared with the NC group

A

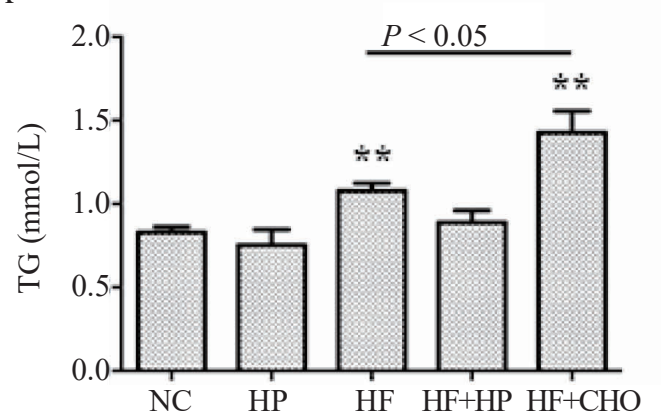

C

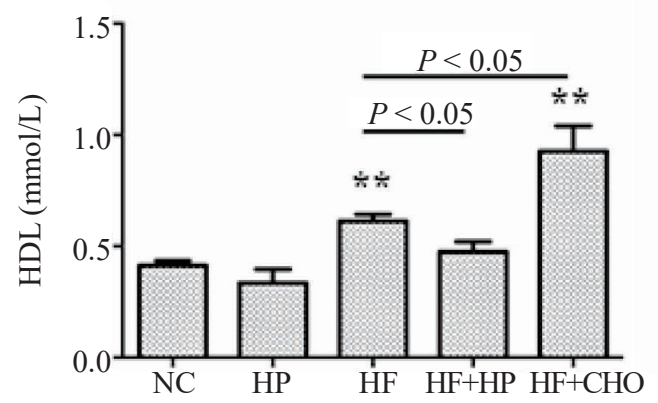

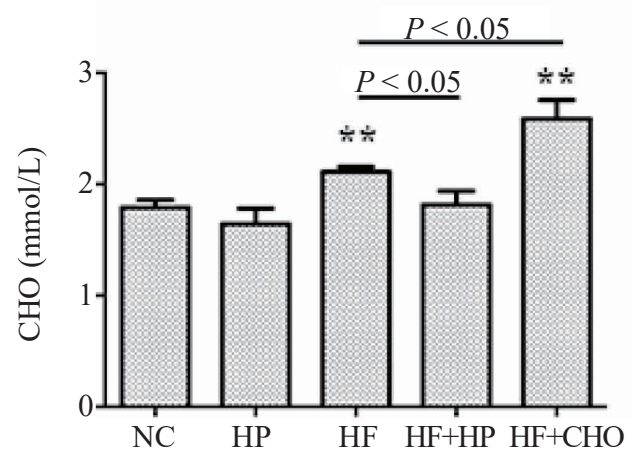

D

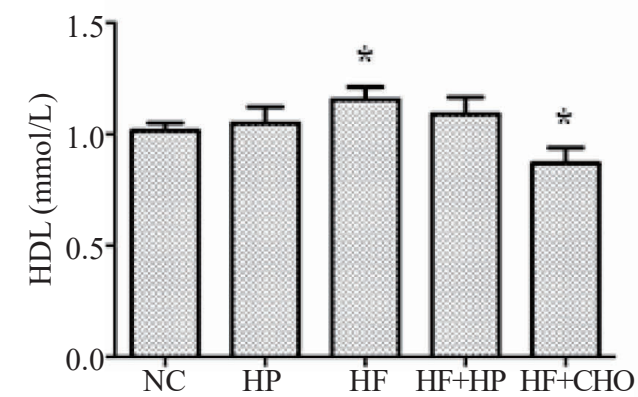

Figure 4 The tryglyceride (TG), total cholesterol (CHO), high-density lipoprotein (HDL) and low-density lipoprotein (LDL) levels in rats fed five different diets for 8 weeks after a $12 \mathbf{h}$ fast. Values are expressed as the means \pm SEM. $* P<$ $0.05, * * P<0.01$ versus the $\mathrm{NC}$ group. 
The level of protein used in the high-protein diet of the rats was $36 \%(\mathrm{~g} / 100 \mathrm{~g})$ in the present study, and the relative energy contributed by protein was $37.6 \%$. The body weights of the animals in the HP group were never significantly different from those in the NC group, which confirmed that a protein diet resulted in weight loss or maintenance $[19,36]$. In addition, the weight gains of rats fed a $\mathrm{HF}+\mathrm{HP}$ diet were similar to those of the rats fed a basal (NC) diet. The HOMA-IR values were also similar in the HP and $\mathrm{NC}$ groups. However, the HF+HP group showed insulin resistance, indicating that the addition of high protein to the HF diet was able to reduce the weight gain associated with the HF diet, but did not suppress the dysregulation of insulin.

A previous study reported a reduction in total and LDL cholesterol and a greater increase in HDL cholesterol in response to increased dietary protein [37]. Our present data showed that there were no significant differences between the HP and NC groups in terms of the effects on the metabolic parameters. The levels of serum metabolic parameters were similar in the $\mathrm{HF}+\mathrm{HP}$ and $\mathrm{NC}$ groups, demonstrating that increasing the protein intake may be useful for ameliorating the metabolic risks associated with high-fat diets. However, it should be kept in mind that the present study was performed in rats, so human studies will be needed before conclusions can be drawn regarding the impact of the different diets on human outcomes.

\section{Conclusions}

The diet containing both high fat and cholesterol was associated with the greatest risk of metabolic syndrome. The $\mathrm{HF}+\mathrm{CHO}$ diet could lead to weight gain, insulin resistance, high blood lipids, and high blood LDL and low HDL, which are all implicated in hypertension and cardiovascular disease. Rats fed a HF+HP diet showed a lower weight gain, but still exhibited increased blood glucose levels and decreased insulin sensitivity. The rats fed a $\mathrm{HF}, \mathrm{HF}+\mathrm{CHO}$ or $\mathrm{HF}+\mathrm{HP}$ diet all developed some level of insulin resistance in our study. In our experiments, HP itself did not induce metabolic syndrome, but it remains unclear whether the HP has adverse effects on the renal system. In practice, in developed and many developing countries, people eat a lot of meat that contains fat, protein and cholesterol, which is not healthy. We suggest that people seeking a high protein food source should select one with less (or no) fat and cholesterol, such as that provided by lean meats and plant sources.

\section{Abbreviations}

NC: normal control diet;

HP: high-protein diet;

HF: high-fat diet;

$\mathrm{HF}+\mathrm{HP}$ : a combination high-protein and high-fat diet;

$\mathrm{HF}+\mathrm{CHO}$ : high-fat with cholesterol diet;

OGTT: oral glucose tolerance test;
HOMA: homeostasis model assessment;

GLU: glucose;

INS: insulin;

TG: triglycerides;

CHO: cholesterol;

HDL: high-density lipoprotein;

LDL: low-density lipoprotein

\section{Conflict of Interests}

The authors declare no conflicts of interest

\section{Funding}

This work was supported by the National Natural Science Foundation of China (NO. 81501226, 81170814, 81370881).

\section{References}

1. Cornier M-A, Dabelea D, Hernandez TL, Lindstrom RC, Steig AJ, Stob NR, Van Pelt RE, Wang H, Eckel RH. The metabolic syndrome. Endocr Rev 2008;29(7):777-822.

2. Eckel RH, Alberti K, Grundy SM, Zimmet PZ. The metabolic syndrome. The Lancet 2010;375(9710):181-3.

3. Paigen B. Genetics of responsiveness to high-fat and high-cholesterol diets in the mouse. Am J Clin Nutr 1995;62(2):458S-62S

4. Groop L. Genetics of the metabolic syndrome. Br J Nutr 2000;83 (1):39.

5. Messier C, Whately K, Liang J, Du L, Puissant D. The effects of a high-fat, high-fructose, and combination diet on learning, weight, and glucose regulation in C57BL/6 mice. Behav Brain Res 2007;178(1):139-45.

6. Bessesen DH. The role of carbohydrates in insulin resistance. J NutrJ Nutr 2001;131(10):2782S-6S.

7. Akiyama T, Tachibana I, Shirohara H, Watanabe N, Otsuki M. Highfat hypercaloric diet induces obesity, glucose intolerance and hyperlipidemia in normal adult male Wistar rat. Diabetes Res Clin Pract 1996;31(1):27-35.

8. Sumiyoshi M, Sakanaka M, Kimura Y. Chronic intake of high-fat and high-sucrose diets differentially affects glucose intolerance in mice. J NutrJ Nutr 2006;136(3):582-7.

9. Brenner RR, Rimoldi OJ, Lombardo YB, González MS, Bernasconi AM, Chicco A, Basabe JC. Desaturase activities in rat model of insulin resistance induced by a sucrose-rich diet. Lipids 2003;38(7):733-42.

10. Pagliassotti MJ, Prach PA, Koppenhafer TA, Pan DA. Changes in insulin action, triglycerides, and lipid composition during sucrose feeding in rats. Am J Physiol Regul Integr Comp Physiol 1996;271(5):R1319-R26.

11. Goodpaster BH, Kelley DE, Wing RR, Meier A, Thaete FL. Effects of weight loss on regional fat distribution and insulin sensitivity in obesity. Diabetes 1999;48(4):839-47.

12. Poirier P, Giles T, Bray G, Hong Y, Stern J, Pi-Sunyer F, Eckel R. Obesity Committee of the Council on Nutrition, Physical Activity, and Metabolism. Obesity and cardiovascular disease: pathophysiology, evaluation, and effect of weight loss: an update of the 1997 American Heart Association Scientific Statement on Obesity and Heart Disease from the Obesity Committee of the Council on Nutrition, Physical Ac- 
tivity, and Metabolism. Circulation 2006;113(6):898-918.

13. McLaughlin T, Abbasi F, Kim H-S, Lamendola C, Schaaf P, Reaven G. Relationship between insulin resistance, weight loss, and coronary heart disease risk in healthy, obese women. Metabolism 2001;50(7):795-800.

14. Tappy L. Thermic effect of food and sympathetic nervous system activity in humans. Rerrod Nutr Dev 1996;36(4):391-8.

15. Baba NH, Sawaya S, Torbay N, Habbal Z, Azar S, Hashim S. High protein vs high carbohydrate hypoenergetic diet for the treatment of obese hyperinsulinemic subjects. Int J Obes Relat Metab Disord. 1999;23(11):1202

16. Piatti P, Monti L, Magni F, Fermo I, Baruffaldi L, Nasser R, Santambrogio G, Librenti M, Galli-Kienle M, Pontiroli A. Hypocaloric high-protein diet improves glucose oxidation and spares lean body mass: comparison to hypocaloric high-carbohydrate diet. Metabolism 1994;43(12):1481-7.

17. Hoffer LJ, Bistrian BR, Young V, Blackburn G, Matthews D. Metabolic effects of very low calorie weight reduction diets. J Clin Invest 1984;73(3):750.

18. Vazquez JA, Kazi U, Madani N. Protein metabolism during weight reduction with very-low-energy diets: evaluation of the independent effects of protein and carbohydrate on protein sparing. Am J Clin Nutr 1995;62(1):93-103.

19. Ropelle ER, Pauli JR, Fernandes MFA, Rocco SA, Marin RM, Morari J, Souza KK, Dias MM, Gomes-Marcondes MC, Gontijo JA. A central role for neuronal AMP-activated protein kinase (AMPK) and mammalian target of rapamycin (mTOR) in high-protein diet-induced weight loss. Diabetes 2008;57(3):594-605.

20. Expert Panel on DetectionEvaluation, Adults ToHBCi. Executive summary of the third report of the National Cholesterol Education Program (NCEP) expert panel on detection, evaluation, and treatment of high blood cholesterol in adults (adult treatment panel III). PNAS 2001;285(19):248697.

21. Pickavance L, Tadayyon M, Widdowson P, Buckingham R, Wilding $\mathrm{J}$. Therapeutic index for rosiglitazone in dietary obese rats: separation of efficacy and haemodilution. Br J Pharmacol 2009;128(7):1570-6.

22. Yeni-Komshian H, Carantoni M, Abbasi F, Reaven G. Relationship between several surrogate estimates of insulin resistance and quantification of insulin-mediated glucose disposal in 490 healthy nondiabetic volunteers. Diabetes Care 2000;23(2):171-5.

23. Matthews D, Hosker J, Rudenski A, Naylor B, Treacher D, Turner R. Homeostasis model assessment: insulin resistance and $\beta$-cell function from fasting plasma glucose and insulin concentrations in man. Diabetologia 1985;28(7):412-9.

24. Bray GA, Lovejoy JC, Smith SR, DeLany JP, Lefevre M, Hwang D, Ryan DH, York DA. The influence of different fats and fatty acids on obesity, insulin resistance and inflammation. J Nutr 2002;132(9):2488-91.

25. Ridker PM, Rifai N, Rose L, Buring JE, Cook NR. Compari- son of C-reactive protein and low-density lipoprotein cholesterol levels in the prediction of first cardiovascular events. N Engl J Med 2002;347(20):1557-65.

26. Pocock SJ, Shaper AG, Phillips AN. Concentrations of high density lipoprotein cholesterol, triglycerides, and total cholesterol in ischaemic heart disease. BMJ 1989;298(6679):998.

27. Jean C, Rome S, Mathé V, Huneau J-F, Aattouri N, Fromentin G, Achagiotis CL, Tomé D. Metabolic evidence for adaptation to a high protein diet in rats. J Nutr 2001;131(1):91-8.

28. Wang W, Liu W, Fidler T, Wang Y, Tang Y, Woods B, Welch C, Cai B, Silvestre-Roig C, Ai D, Yang YG, Hidalgo A, Soehnlein O5, Tabas I, Levine RL, Tall AR, Wang N. Macrophage Inflammation, Erythrophagocytosis, and Accelerated Atherosclerosis in Jak2 (V617F) Mice. Circ Res 2018;123(11):e35-e47. doi: 10.1161/circresaha.118.313283.

29. Proto JD, Doran AC, Subramanian M, Wang H, Zhang M, Sozen E, Rymond CC, Kuriakose G, D'Agati V, Winchester R, Sykes, M, Yang YG,Tabascorresponding I . Hypercholesterolemia induces T cell expansion in humanized immune mice. J Clin Invest 2018;128(6):2370-5. doi: $10.1172 /$ jci97785.

30. Shin JY, Xun P, Nakamura Y, He K. Egg consumption in relation to risk of cardiovascular disease and diabetes: a systematic review and meta-analysis. Am J Clin Nutr 2013;98(1):146-59. doi: 10.3945/ ajcn.112.051318.

31. Hu FB, Stampfer MJ, Rimm EB, Manson JE, Ascherio A, Colditz GA, Rosner BA, Spiegelman D, Speizer FE, Sacks FM, Hennekens CH, Willett WC. A prospective study of egg consumption and risk of cardiovascular disease in men and women. JAMA 1999;281(15):1387-94.

32. Feig JE, Rong JX, Shamir R, Sanson M, Vengrenyuk Y, Liu J, Rayner K, Moore K, Garabedian M, Fisher EA. HDL promotes rapid atherosclerosis regression in mice and alters inflammatory properties of plaque monocyte-derived cells. PNAS 2011;108(17):7166-71.

33. Tikkanen MJ, Huttunen J, Ehnholm C, Pietinen P. Apolipoprotein E4 homozygosity predisposes to serum cholesterol elevation during high fat diet. Arterioscler Thromb Vasc Biol 1990;10(2):285-8.

34. Westerterp-Plantenga MS, Nieuwenhuizen A, Tome D, Soenen S, Westerterp KR. Dietary protein, weight loss, and weight maintenance. Annu Rev Nutr 2009;29:21-41.

35. Lacroix M, Gaudichon C, Martin A, Morens C, Mathe V, Tome D, Huneau JF. A long-term high-protein diet markedly reduces adipose tissue without major side effects in Wistar male rats. Am J Physiol Regul Integr Comp Physiol 2004;287(4):R934-42.

36. Gordon DJ, Probstfield JL, Garrison RJ, Neaton JD, Castelli WP, Knoke JD, Jacobs Jr DR, Bangdiwala S, Tyroler H. High-density lipoprotein cholesterol and cardiovascular disease. Four prospective American studies. Circulation 1989;79(1):8-15.

37. Wolfe BM, Giovannetti PM. Short-term effects of substituting protein for carbohydrate in the diets of moderately hypercholesterolemic human subjects. Metabolism 1991;40(4):338-43. 